\title{
Digitale læringsressurser i høyere musikkutdanning
}

\author{
Maria Medby Tollefsen \\ UiT - Norges arktiske universitet \\ Hilde Synnøve Blix \\ UiT - Norges arktiske universitet
}

\begin{abstract}
Sammendrag
Artikkelens tema er bruk av digitale læringsressurser i høyere musikkutdanning, og den fokuserer på hvorvidt og på hvilke måter slike læringsressurser kan brukes for å fremme kreativitet, kritisk refleksjon og selvstendig tenking. Artikkelen åpner med noen betraktninger rundt den økende bruken av digitalt lærestoff $\mathrm{i}$ høyere utdanning generelt, og i høyere musikkutdanning spesielt. Deretter redegjøres det for en undersøkelse utført høsten 2016, som ser på dagens musikkstudenters bruk av og holdninger til digitale læringsressurser. Videre drøftes fordeler og mer problematiske sider ved bruk av digitalt læremateriale i studiesammenheng, sett ut fra målet om å stimulere studentenes evne til kreativitet, kritisk refleksjon og selvstendig tenking. Som et bakteppe for drøftingen ligger kritisk-pedagogisk teori slik den blir brukt av tenkere som Giroux og Freire. På bakgrunn av drøftingen antydes noen didaktiske implikasjoner studien gir.
\end{abstract}

\section{Nøkkelord: Digitale laringsressurser; musikkpedagogikk; høyere musikkutdanning; kritisk pedagogikk}

\begin{abstract}
This article is concerned with the use of digital learning and teaching resources in higher music education, and focuses on whether and how these resources can be used to encourage creativity, critical reflection, and independent thinking. The article opens with a discussion of the general increase in the use of digital teaching materials in higher education, particularly in music. It then presents research carried out in autumn 2016, which considers current music students' use of and attitudes towards digital learning resources. The article then moves on to a discussion of the advantages and problems with the use of digital learning resources in teaching and learning when the goal is to stimulate students' capacity for creativity, critical reflection, and independent thinking. The theoretical background to the study is critical pedagogical theory, particularly the ideas of Giroux and Freire, together with a discussion of the didactical implications of the research.
\end{abstract}

Keywords: Digital learning resources; music pedagogy; higher music education; critical pedagogy

^Korrespondanse: Maria Medby Tollefsen, UiT Norges arktiske universitet, Postboks 6050 Langnes, 9037 Tromsø. Epost: maria.m.tollefsen@uit.no

(C) 2018 Maria Medby Tollefsen, Hilde Synnøve Blix.This is an Open Access article distributed under the terms of the Creative Commons Attribution 4.0 International License (https://creativecommons.org/licenses/by-nc/4.0/), allowing third parties to copy and redistribute the material in any medium or format and to remix, transform, and build upon the material for any purpose, even commercially, provided the original work is properly cited and states its license. Citation: Maria Medby Tollefsen, Hilde Synnøve Blix. «Digitale leringsressurser $i$ høyere musikkutdanning». Fournal for Research in Arts and Sports Education, Special Issue: «Skapende og tenkende - Perspektiver på kritisk kunstpedagogikk $i$ skole og kulturliv»Vol. 2(2), 2018, pp. 35-47. http://dx.doi.org/10.23865/jased.v2.918 35 
Received: June, 2017; Accepted: May, 2018; Published: July, 2018

\section{Innledning}

Et mål med høyere utdanning i musikk er å utdanne «utøvere og musikkpedagoger som har evne og vilje til å bidra til utvikling og endring innenfor sine fagfelt» (uit. no). En forutsetning for å kunne realisere en slik visjon, er at studentene gjennom studiet utvikler kreativitet, kritisk refleksjon og selvstendig tenking. I denne artikkelen vil perspektiver fra kritisk pedagogikk gi retning til en diskusjon om forholdet mellom digitale læringsressurser og studentenes egeninnsats i utviklingen av kreativitet, kritisk refleksjon og selvstendig tenking:

Critical pedagogy asserts that students can engage their own learning from a position of agency and in so doing can actively participate in narrating their identities through a culture of questioning (...).

(Giroux, 2011, s. 14)

Den tradisjonelle instrumentalundervisningen i skandinavisk musikkutdanning minner på mange måter om mesterlæretradisjonen som gjennom historien har vært vanlig i opplæringen i ulike håndverk (Nielsen \& Kvale, 1999). Denne typen undervisning har flere styrker, deriblant den tette og nøye tilrettelagte oppfølgingen studenten får, og at studenten via sin lærer tilegner seg kunnskap om koder, normer og etikk som gjelder innenfor profesjonen. Metodikken forutsetter et gitt tankesett rundt det som skal læres. Faglige tradisjoner er ofte styrende for veiledningen, og det at studenten har en kritisk reflekterende holdning til de gjeldende tradisjonene, er ikke nødvendigvis vektlagt. Sett i en musikkutdanningskontekst vil dette kunne bidra til å konservere måten musikk utøves, formidles og undervises på, og dermed stå i veien for utvikling og endring. En kritisk pedagogikk i musikkutdanningene, som en motvekt eller tillegg til den mesterlærelignende undervisningen, vil kunne være et middel for å fremme kreativitet og kritisk tenkning og dermed legge til rette for at studentene utvikler evnen til å reflektere kritisk rundt gjeldende tradisjoner og standarder.

Selv om hovedinstrumentundervisningen er en hjørnestein i musikkstudentenes lærings- og danningsprosesser, er det en rekke andre faktorer som har betydning for disse prosessene, deriblant de lærere studenten møter i de øvrige av studiets emner, faglitteratur, medstudenter og studentens musikalske liv utenfor studiestedet. I dag utgjør også digitale medier en faktor som vil ha betydning for hva og hvordan studenten lærer.

Den tilgjengelige mengden digitalt, nettbasert læremateriell ${ }^{1}$ er stadig økende, og studentene vi har intervjuet $\mathrm{i}$ den foreliggende studien rapporterer at de bruker slike læringsressurser som en integrert del av sitt studium. Digitalt lærestoff kan brukes til å støtte opp under undervisningsformer som konserverer og viderefører gjeldende tradisjoner innenfor musikkutdannelse og musikkutøvelse, men det fins også måter

\footnotetext{
${ }^{1}$ Digitalt laremateriale brukes synonymt med digitale laringsressurser og digitalt larestoff.
} 
å bruke digitale læringsressurser på som kan fremme utviklingen av kreativitet, egenart og evne til å kunne reflektere kritisk rundt etablerte tradisjoner og standarder. Kritisk bevissthet rundt valg og bruk av digitalt læremateriell er avgjørende for å kunne utnytte slike ressurser på en måte som stimulerer til innovativ kunstnerisk virksomhet og kritisk refleksjon rundt egen kunstnerisk praksis.

Denne artikkelen fokuserer på bruk av digitale læringsressurser i høyere musikkutdanning med utgangspunkt i spørsmålene: Hvilke typer digitale leringsressurser bruker musikkstudenter $i$ høyere utdanning, på hvilken måte brukes ressursene og hva slags holdninger har studentene til bruk og valg av digitalt laremateriell? Vi spør også: Hvilke didaktiske konsekvenser har tilgangen på og bruken av slike ressurser for musikkutdanningene?

Artikkelens første del beskriver den stadig økende interessen for å bruke digitale læringsressurser i høyere utdanning generelt, og hvordan dette gir seg utslag ved musikkutdanningsinstitusjonene. I andre del av artikkelen redegjøres det for det empiriske materialet som denne artikkelen bygger på med en påfølgende drøfting av studiens funn. Kritisk pedagogisk teori slik den blir brukt av pedagogiske tenkere som Henry Giroux og Paulo Freire, ligger til grunn for drøftingen.

\section{Forskningsmessig og teoretisk bakgrunn}

Siden millenniumskiftet har det vært en enorm fremvekst av digitale, nettbaserte læringsressurser. Forventningene til økt bruk av digitale verktøy og nettbaserte læremidler i høyere utdanning er store, både fra statlig hold, fra utdanningsinstitusjonene selv og fra studentene. Digital teknologi gir nye pedagogiske og didaktiske muligheter, og i tillegg er digital kompetanse nødvendig når studentene skal ut i arbeidslivet. Kvalitetsreformen ${ }^{2}$ formulerer forventningene om bruk av digital teknologi i utdanning slik:

Det ligger et stort potensial i bruk av IKT i undervisning, læring og kompetanseutvikling. Utdanningssystemet må legge opp utdanningstilbudene slik at dette potensialet kan realiseres.

(Stortingsmelding 27, s. 8)

Også internasjonalt satses det på digital teknologi og digitale læringsressurser for å utvikle og forbedre undervisningen i høyere utdanning. Europakommisjonen har publisert dokumenter som "Modernisation of higher education» (2014) og «Opening up education: Innovative teaching and learning for all through new technologies and Open Educational Resources» (2013). Disse dokumentene fremhever betydningen av å bruke digital teknologi i forbindelse med undervisning og læring.

I pedagogisk forskning stilles blant annet spørsmål som går på hvilke måter digital teknologi kan bidra til at læring sentreres rundt forståelse og anvendelse av kunnskap snarere enn rundt reproduksjon av kunnskap (Fossland, 2015, s. 226). En finsk studie så på måten elever på yrkesutdanninger tok i bruk læringsplattformen personal learning environment (PLE), og konklusjonene viste fire hovedretninger i måten elevene

${ }^{2}$ Stortingsmelding nr. 27 (2000-2001) Gjør din plikt - Krev din rett. 
bygde opp sine egne digitale læringsressurser på: a) en kopi av det konvensjonelle læringsmiljøet, b) et miljø for refleksjon, c) et miljø for å vise fram ferdighetene sine og d) et miljø for samarbeidslæring og nettverksbygging (Valtonen, Hacklin, Dillon, Vesisebaho, Kukkonen \& Hietanen, 2012). Mye av forskningen gjort på bruk av digitale læringsressurser i høyere utdanning fokuserer på bruk av læringsplattformer som Fronter og It's Learning (Ørnes, Gaard, Refsnes, Kristiansen \& Wilhelmsen, 2011), og vi finner få studier som tar for seg den fulle bredden av digitale læringsressurser studenter bruker for å tilegne seg studierelevant kunnskap (Rønning \& Grepperud, 2006).Vi ser likevel en økende mengde studier som tar inn over seg en endring i nettbruk der aktiv deltakelse fra brukerne og sosiale nettjenester kreves, såkalt web 2.0. ${ }^{3}$ I det pedagogiske feltet foreligger det etter hvert også en god del studier som ser på hvordan lærere bruker og velger nettressurser i sin undervisning. Lærernes teknologiske kompetanse har økt betydelig de senere årene, og nye teknologiske løsninger betraktes i større grad som laringsteknologi og ikke bare hjelpemidler i undervisningen (Helleve, Almås \& Bjørkelo, 2016).

Ifølge Norgesuniversitetets rapport «Digital tilstand 2014» tilrettelegger de fagansatte i høyere utdanning relativt sjelden for bruk av digitale læringsressurser, og studenter savner flere digitale ressurser enn det utdanningsinstitusjonene legger opp til. Det rapporteres i tillegg sjelden om utforsking og kreativ skapende bruk av digitale verktøy i utdanningene (Ørnes et al., 2015). Undersøkelser viser også at flertallet av dagens studenter ønsker mer bruk av digitalt lærestoff $\mathrm{i}$ undervisningen, og dessuten mer opplæring i bruken av slikt materiell (Fossland, 2015; Ørnes et al., 2015).

Som med mange nyvinninger igjennom historien, fins det både en stor skepsis og en stor iver i forhold til det å bruke digital teknologi i undervisning. I høyere utdanning er det særlig den yngre genereasjonen lærere som er aktive når det kommer til å utvikle og benytte digitale læringsressurser i pedagogisk sammenheng (Fossland, 2015). Denne generasjonen lærere er vokst opp i en tid der digitale verktøy som datamaskiner, nettbrett og mobiltelefon er en naturlig del av hverdagen (Tapscott, 2009), og det er derfor nærmest forventet at de er pådrivere for den teknologiske utviklingen også innen utdanning.

Høyere musikkutdanning skiller seg fra majoriteten av studieprogram $i$ universitetsog høgskolesektoren på den måten at undervisningen ofte foregår én til én eller $\mathrm{i}$ små grupper, og at det gjerne er snakk om erfaringsbasert læring og utøvende og/ eller praktiske fag. Behovet for bruk av digitale læringsressurser og fleksible læringsformer er ikke like fremhevet i musikkutdanningsinstitusjonenes strategiplaner som det er i planene for andre utdanningsforløp og fagfelt. Allikevel formulerer flere av utdanningsinstitusjonene et ønske om å nyttiggjøre seg de mulighetene digital teknologi tilbyr for å utvikle og optimalisere undervisning, noe som blant annet kan sees i Norges Musikkhøgskoles strategiplan frem mot 2025: «Vi skal ta i bruk ny teknologi som fremmer samhandling, kunnskapsdeling og effektivitet». På grunn av tradisjonen med nokså individrettet undervisning, og at forelesningsformen er lite utbredt, vil det være behov for andre typer, og mer individuelt tilpassede, digitale ressurser i

${ }^{3}$ https://en.wikipedia.org/wiki/Web_2.0 
musikkutdanning enn i en del andre utdanninger. Musikkutdanningenes mesterlærelignende undervisningstradisjon, og dens implisitte videreformidling av standarder, holdninger og interpretasjonstradisjoner, aktualiserer spørsmålet om hvordan digital teknologi kan bidra til at læring dreier seg om refleksjon, forståelse og innovativ anvendelse av kunnskap og ferdigheter heller enn konservering og reproduksjon.

Den følgende presentasjonen og drøftingen av studiens funn har som teoretisk fundament et kritisk pedagogisk perspektiv bygd på de pedagogiske teoretikerne Paulo Freire (1974) og Henry Giroux (2011). Hos begge står endring av en rådende pedagogisk praksis sentralt, med særlig fokus på den lærendes muligheter til å være aktivt deltakende i egne læringsprosesser og utvikling av kritisk bevissthet. I tillegg er begge opptatte av utdanningens rolle i utviklingen av demokratiske samfunn. I et intervju sier Giroux om dataalderen at:

The Internet is a form of pedagogy, because it both produces knowledge and facilitates the exchange of knowledge and communications; it deals with the ongoing exchange and legitimation of values, it deals with dialogue, it deals with ways in which people produce meaning. ${ }^{4}$

Fordi teknologien har ført til at blyant er byttet ut med datamaskin og bøker med internett, er individets kunnskapsdannelse blitt ytterligere individualisert, og i henhold til Giroux (2011) avhenger et kritisk, opplyst demokrati av den enkeltes evne og vilje til å velge kritisk og kunnskapsbasert. Dette stiller også større krav til utdanningsinstitusjonenes innsats for å gi studentene redskap til å utvikle kreative, kritiske evner.

There is too little understanding of the educative nature of such technologies. They are educative in the most fundamental political sense. They have an enormous reach, they have enormous power, they influence enormous amounts of people, and they constitute a power element of how the political is constituted. One could argue that the ways people now read society, read culture, read politics, is almost entirely now through the Internet.

(Giroux i intervju med Jandric)

Med bakgrunn i nettbaserte læringsressursers «utdannende natur» gjorde vi en undersøkelse der målet var å få kunnskap om musikkstudenters bruk av slike læringsressurser, samt hvilke holdninger studentene har til bruk og kritisk vurdering av disse. I siste del av artikkelen drøftes didaktiske konsekvenser for musikkutdanning som følge av valg og bruk av digitale læringsressurser. Drøftingen tar utgangspunkt i resultater som fremkom gjennom undersøkelsen.

\section{Bruk av digitale læringsressurser blant musikkstudenter}

\section{Metode, data og utvalg}

Studien som omtales her, ble gjennomført ved UiT - Norges arktiske universitet, Musikkonservatoriet, høsten og vinteren 2016/2017. Målet var å få innsikt i utøvende

${ }^{4}$ Henry Giroux intervjuet av Petar Jandric (2015): http://www.cjournal.info/2015/06/18/criticalpedagogy-in-and-for-the-age-of-the-digital-media-pedagogy-of-the-precariat/ Hentet 15.05.2018. 
musikkstudenters vaner og holdninger vedrørende bruk av digitale læringsressurser. Det empiriske materialet ble samlet inn ved hjelp av intervjuer og spørreskjemaer, og til sammen tjue studenter deltok i studien. Forespørsel om deltakelse i studien ble gjort gjennom en e-post til alle studentene på BA-utdanningen, omtrent 60 studenter, og utvalget i studien består av studentene som meldte seg frivillig til å svare på undersøkelsens spørsmål.

Begrunnelsen for bruk av spørreskjema i tillegg til intervjuene var behovet for en større mengde og bredde i informasjonen om bruk av digitale læringsressurser enn det intervjuundersøkelsen ga. Denne typen kombinerte metoder gir muligheten til å besvare forskningsspørsmålene med både kvantitative og kvalitative data, noe vi mente ville styrke undersøkelsens funn (Johnson, Onwuegbuzie \& Turner, 2007).

Det var tilsammen åtte studenter som ble intervjuet, og deretter svarte tolv andre studenter på utdelt spørreskjema. Utgangspunktet for spørreskjemaet var de samme spørsmålene som i intervjuene, men med tillegg av spørsmål med flervalgsmuligheter, der studentene krysset av for hvilke faktorer de anså som mer eller mindre betydningsfulle i valg av digitale læringsressurser. Informantene besto av studenter på bachelorstudiet i musikkutøving ved Musikkonservatoriet i Tromsø. Studenter innen både klassisk og rytmisk sjanger var representert, samt studenter av begge kjønn og fra alle fire studieår. Studentene ble spurt om følgende tematikker: typer nettsteder/apper/programvare/ blogger som brukes, veiledning i bruk av ressurser ved utdanningen, og deres refleksjoner knyttet til valg og vurdering av digitalt lærestoff.

I framstillingen markeres de studentene som svarte skriftlig slik: (Survey A, B, C etc.), og de intervjuede studentene slik: (Int I, J, K etc.). Dette for å skille mellom svarene som kom ved at forskeren var i direkte kontakt med studenten, og spørreskjemasvarene hvor studentene hadde tid til å vurdere sine svar og uten oppfølgingsspørsmål fra forskeren.

Studiens data ble analysert med basis i tematikken i intervjuspørsmålene, og drøftes med utgangspunkt i den kritiske pedagogikkens perspektiv på kreativitet, kritisk refleksjon og selvstendig tenkning (Freire, 1974; Giroux, 2011).

\section{Typer digitale læringsressurser}

Gjennom undersøkelsen kom det frem at studentene jevnt over er positive til bruk av digitale læringsressurser i studiesammenheng. Alle informantene bruker slike ressurser, men i varierende grad. Det fins mange ulike typer digitale læringsressurser. I det følgende redegjøres det for de ressursene som ble framhevet av studentene som mest relevante for dem i sin musikerutdanning, og da spesielt med tanke på utøvende og praktiske emner i studiene. Vi har i denne sammenhengen valgt å dele læringsressursene i to hovedkategorier: Læringsressurser med definert faglig innhold og progresjon og læringsressurser som gir didaktiske og metodiske muligheter uten nødvendigvis å ha en spesifisert faglig funksjon.

Digitale læringsressurser i den første kategorien består blant annet av apper, nettsteder og programvare. Det tilbys slikt læremateriale blant annet i emner som gehørtrening, 
musikkhistorie og musikkteori. Appene/nettstedene/programvaren kan ligne tradisjonelle lærebøker i oppbygning, men har gjerne en mer interaktiv innretning. Eksempel på slik programvare er gehørtreningsprogram som EarMaster. ${ }^{5}$ Programmer som dette er didaktisk strukturerende læringsressurser der brukeren følger en bestemt progresjon, og der læringsmål gjerne er definert. Denne type materiale egner seg i mange tilfeller til selvstudium. Det giør at studenter som har behov for mer undervisning, eller undervisning i et annet tempo enn det som tilbys gjennom studiet, har mulighet til å skaffe seg det. Det giør også at kunnskapen kan formidles til mange, også til grupper av befolkningen som ellers ikke ville ha hatt tilgang på undervisning. Det ble også trukket fram læremateriale i denne første kategorien som har en mer didaktisk supplerende funksjon. Eksempler på slikt materiale er nettstedene musikkteori.net, klassisk-harmoni.no, musicificium.no og trell.org, som henholdsvis tilbyr læremateriale i musikkteori, hørelære og musikkhistorie. Slikt lærestoff har gjerne et klart faglig innhold og oppbygning, men fordrer ikke at studentene følger en bestemt progresion eller bestemte arbeidsmåter. Siden lærestoffet som regel er tilgjengelig for alle og enhver, kan det brukes både av studenter som har behov for utfyllende lærestoff og av lærere som trenger supplerende læremateriale i planlegging og gjennomføring av undervisning.

Læringsressurser i den andre kategorien har vi valgt å kalle digitale didaktiske verktøy. I mange tilfeller åpner disse læringsressursene opp for didaktiske muligheter som ikke tidligere var mulig, eller som før krevde en større arbeidsinnsats. Her følger en oversikt over de digitale læringsressurser som ble rapportert brukt både i undervisningstimene og i studentenes egenarbeid med studiet:

- Streamingkanaler som YouTube, Spotify og Tidal. Slike verktøy gir studentene tilgang på en stor mengde innspillinger av musikk og opptak av konserter, forestillinger, masterclasses, foredrag etc.

- Kommunikasjonsverktøy som Adobe Connect og Skype, sosiale medier som Facebook, læringsplatformer som Fronter, Canvas og It's learning. Slik programvare letter kommunikasjonen og giør det blant annet også mulig å ha undervisning med lærere som befinner seg langt unna geografisk.

- Fildelingsverktøy som Dropbox og Box. Slik programvare brukes blant annet til å dele noter og lyd- og videoopptak.

- Nettsteder og apper for nedlasting, oppbevaring og redigering av noter, som ForScore og IMSLP.

- Programvare for oversettelse, uttale og gjendikting av tekst tilknyttet musikk, som IpaSource og Lieder.net.

- Programvare for digital notasjon og redigering av musikk, som Sibelius, Finale, ProTools og Transcribe!

- Programvare som gir studentene muligheten til å øve på konkrete, musikalske ferdigheter: iReal Pro, drum beatsy tempo, time trainer, Capo, Perfect Ear 2, Medici, Goodear pro.

${ }^{5}$ Interaktiv programvare til bruk i gehørtrening. Produsert av EarMaster ApS. 
- Apper som inneholder tuner, minipiano, metronom og lignende.

- Oppslagsverk som Store Norske Leksikon og Wikipedia

Som vi ser, er nettressursene studentene nevner svært mangfoldige. Hvis man ser på de som brukes mest, er YouTube, Spotify og Wikipedia hovedkildene til kunnskap, og Sibelius og ProTools er de mest brukte verktøyene for å skape musikk. De to sistnevnte er tilgjengelige via utdanningsinstitusjonen, og også de verktøyene det undervises i gjennom emnene musikkteknologi og komponering/arrangering. Det er verdt å merke seg at bredden i nettressursene studentene bruker, i stor grad er drevet av egeninteresse, meningsfellers erfaringer og instrumentspesifikke behov. Dette fremkommer blant annet i svarene på spørsmål om det er læreres eller medstudenters tips om ressurser studentene støtter seg på når de velger blant digitale ressurser.

Fordelene med digitale læringsressurser vil, også innenfor musikkutdanningen, variere fra emne til emne. Men en av de store gevinstene er at materialet kan være multimedialt: altså inneholde kombinasjoner av noter, bilde, lyd, video og tekst. Muligheten til å produsere multimedialt lærestoff letter blant annet arbeidet med å lage læremateriale der auditive opplevelser og erfaringer danner utgangspunktet for læring. Med slike erfaringer som fundament, kan det være enklere å legge opp til en undervisning der studentens refleksjon over det erfarte står sentralt i arbeidet. Det vil også kunne gjøre det enklere å gjøre undervisningen praksisnær og på den måten øke studentenes motivasjon til å jobbe med materialet.

Moderne streamingteknologi gjør det enkelt å lytte til eller å se på flere innspillinger eller fremføringer av ett og samme verk, og undersøkelsen viser at studentene benytter seg av dette i stor grad. Tilgangen på innspilt lyd er en betydningsfull læringsressurs i musikkstudiet, både for lærere i planleggingen av undervisning, for studenter som studerer hovedinstrumentrepertoar, og i arbeid med støtteemnene.

\section{Kritisk bevisste valg eller «det de andre bruker»?}

Digital teknologi rettet mot undervisning er spennende, og mange studenter og lærere tar i bruk slike læremidler med stor entusiasme. En av de store utfordringene med digitale læringsressurser er at de ofte gir mange svar og mye informasjon, uten krav til at brukeren reflekterer rundt eller forholder seg kritisk til lærestoffet. Dette kan bidra til en undervisning der studentene er mer eller mindre passive mottakere av kunnskap, og der de i liten grad utvikler evnen til kritisk og kreativ tenkning. Giroux mener at dagens undervisning i den vestlige verden tenderer mot å være instrumentell og passiviserende:

Pedagogy is largely reduced to a transmission model of teaching and limited to the propagation of a culture of conformity and the passive absorption of knowledge.

(Giroux, 2011, s. 5)

Funnene fra undersøkelsen viser at studentenes bevissthet rundt problematiske sider ved digitale læringsressurser er varierende. De fleste informantene nevnte 
nødvendigheten av kildekritikk i møtet med tekstbaserte læringsressurser, hovedsakelig for å forsikre seg om at det skrevne er til å stole på. Flere informanter mente likevel at de ikke er så kritiske i valg og bruk av materialet som de burde være:

Hvis det ikke er noe veldig oppsiktsvekkende ved det jeg leser, svelger jeg det rått. Det kan hende, hvis jeg tenker mye på det, at jeg giør meg refleksjoner rundt det. Men der og da tar jeg det ofte for god fisk.

(Int M)

Informantene hadde generelt liten bevissthet rundt problematiske aspekter ved digitale læringsressurser utover det som går på sannhetsgehalten i lærematerialet. Eksempelvis oppga de fleste pris og brukervennlighet som avgjørende faktorer i valg av læringsressurser, noe som de mente kunne gå på bekostning av innholds- og kildekritikk. Forholdet mellom marked og kvalitet er et sentralt spørsmål i alle typer vurderinger av kunnskapskilder i dag. Studenter er vante til å være kritiske til markedsføring generelt, og mange av studentene i undersøkelsen sier at såkalte brukervurderinger av nettressurser er helt uvesentlige når de velger kilder til kunnskap. Vi tolker dette som at studentenes digitale kompetanse også omfatter en skepsis til troverdigheten av brukervurderinger, og at de kjenner til mulighetene for såkalt opinion spam (Ott, Choi, Cardie \& Hancock, 2011). Flere studenter uttrykker likevel et ønske om mer veiledning i hva som er gode nettressurser og hvordan man bør orientere seg i disse.

Studentene rapporterte at de i svært liten grad får veiledning gjennom studiet $\mathrm{i}$ å finne og å bruke digitale læringsressurser. Flere informanter ga tydelig uttrykk for et ønske om mer veiledning fra sine lærere når det gjelder å finne kvalitativt godt materiale på nett:

Jeg skulle ønske at lærerne hadde mer tips i forhold til nettbasert materiale. (...) vi er jo på internett, vi bruker disse tingene. Det er en aktiv del av livet vårt. Man skal ikke kun bruke dette, men materiale som ligger på nett er veldig nyttig. _ (Int J)

I tillegg til å avdekke et behov for veiledning i å finne godt digitalt læremateriale, tydeliggiør studien også studentenes behov for å få synliggiort problematiske sider ved digitalt læremateriell. Dette viser nødvendigheten av en undervisning som gir studentene ballast til å vurdere det lærematerialet de finner på nett, både i forhold til gyldighet, kvalitet, verdigrunnlag og egnethet. Freires kritisk pedagogiske tenkemåte og metode er skapt av behovet for nettopp en slik utvikling av de lærendes egen endringsvilje og handlingskompetanse (Freire, 1974).

Samtidig som studentene oppgir at de får lite eller ingen veiledning i å velge ut kvalitativt gode læringsressurser på nett, mener over halvparten av informantene at det desidert viktigste kriteriet for valg av ressurser er deres egen kvalitetsvurdering av dem.Vi har ikke data som sier noe om hva disse kvalitetene er, men tolker svarene slik at opplevelsen av at ressursen er kvalitativt god er viktigere enn faktorer som design, kompatibilitet med mobiltelefon, markedsføring og synlighet. En mer konkret innsikt i hva studenter legger i kvalitetsbegrepet, og hvordan de vurderer brukervennlighet og design, er svært spennende tematikker for videre forskning. 
Vi spurte studentene hvorvidt de vektla råd fra lærere eller medstudenter når de valgte blant de mange tilgjengelige digitale læringsressursene på nettet, og her var svarene nokså inkonsistente. Det er ingenting i svarene som tyder på at det er viktigere for studentene å følge medstudenters råd enn lærernes. Vi antar at nettressursenes kobling til faget og læreren, i hvor stor grad nettressursen brukes aktivt $\mathrm{i}$ undervisningen, og om materialet er en obligatorisk del av undervisningen, spiller inn når det gjelder hvor mye de anbefalte nettressursene blir brukt.

\section{Ny teknologi: utfordringer og muligheter i musikkutdanningene}

Troen på at bruk av digitale læringsressurser kan øke undervisningskvaliteten, er en forutsetning for at det skal brukes tid og ressurser på å utvikle slikt læremateriale, og for at de som underviser skal bruke energi på å sette seg inn i materialet. På hvilke måter kan digitale læringsressurser bidra til å øke kvaliteten på undervisningen i høyere musikkutdanning, særlig med tanke på å stimulere evnen til kreativitet og refleksjon hos studentene? Hvilke fordeler har digitale læringsressurser sammenlignet med tradisjonelt undervisningsmateriale?

Tradisjonelt er det læreren som velger ut pensumlitteratur og andre læringsressurser til bruk i et emne, og lærerens preferanser og faglige ståsted er dermed styrende for utvalget av læringsressurser. Før vår tids digitale revolusjon måtte studenten ha en betydelig oversikt for å finne læremateriale der et emne eller tema ble belyst, beskrevet eller utført ut fra andre synsvinkler og diskurser enn den læreren formidlet gjennom undervisningen. De digitale læringsressursene har fordelen av å være søkbare på en annen måte enn bøker og annet læremateriale. Det gjør det enklere for den kritisk bevisste student å finne alternativt læremateriale i tilknytning til et emne eller tema, eller i sammenheng med et verk eller en komponist studenten arbeider med. Eksempelvis kan musikkstudenten oppsøke og sammenligne ulike noteutgaver av et verk, forskjellige innspillinger av verket, og videoer der ulike lærere arbeider sammen med utøvere i å tolke verket. Ved å gjøre slike anstrengelser, vil studenten kunne få en innsikt i verket som supplerer, eller avviker fra, det som har blitt formidlet gjennom den tradisjonelle hovedinstrumentundervisningen. Tilgangen på slikt materiale gir også lærere mulighet til å gjennomføre en problembasert undervisning der studenten gjennom analyse og sammenligning av ulike innspillinger, ulike noteutgaver av et verk eller liknende skal komme frem til sin egen tolkning av verket. Slik kan digitale læringsressurser bidra til at etablerte tankemåter, fremføringspraksis og liknende utfordres, nettopp fordi studenten er nødt til å forholde seg kritisk og reflekterende til materialet hun eller han jobber med.

I musikkutdanningenes mange praktiske/utøvende emner handler undervisningen ofte om å finne gode strategier og arbeidsmåter. Slikt arbeid kan være utfordrende. Når studentene øver på egen hånd uten en lærer som støtter dem, er det enklere å ta i bruk allerede innarbeidede strategier enn nye strategier som ikke ennå er internaliserte. Digitalt læremateriale kan være til hjelp i denne prosessen ved å understøtte studentenes øveprosess og gjøre det enklere for dem å repetere det lærte utenom undervisningstimene (Fossland, 2015). 
Det fins en forholdsvis stor mengde digitale læringsressurser innen de ulike emnene i musikkutdanningen, og vi har sett at studentene som deltok i studien bruker en hel rekke forskjellige ressurser. Tilgangen på mye ulikt materiale om samme tema kan bidra til å gjøre undervisningen mer variert. Det kan også giøre det enklere for studenten å finne supplerende materiale der hvor vedkommende ønsker å fordype seg $\mathrm{i}$ temaer som er spesielt utfordrende eller interessante. Det digitale lærestoffet har også den fordelen at det er miljøvennlig og økonomisk sammenlignet med bøker, og det kan dessuten oppdateres kontinuerlig etter hvert som ny viten forandrer pensum eller tilnærming til faget, eller etter hvert som den digitale teknologien utvikles.

Den kritisk pedagogiske retningen står for en kritikk av og en motvekt til en lærerstyrt og behavioristisk undervisningsideologi, og kritisk-pedagogiske tenkere foreslår undervisningsformer som stimulerer studentenes evne til refleksjon og kritikk. Giroux (2011) trekker frem innholdsanalyse av lærestoff som en viktig del av undervisning. Han understreker betydningen av å lære studentene å stille kritiske spørsmål ved et læremateriale, både når det gjelder materialets innhold, hvem som har laget det, samt hvilke verdier lærestoffet bygger på. I møte med digitale læringsressurser vil slike spørsmål være spesielt krevende. For å publisere lærestoff på nett kreves det ingen redaksjonell godkjenning, ingen fagfellevurdering, oftest ikke noen kvalitetsvurdering av noe som helst slag. I utgangspunktet kan hvem som helst publisere hva som helst, så lenge det ikke strider mot nasjonal eller internasjonal lov. Det betyr at kunnskap om og bevissthet rundt hvem som har produsert et lærestoff, er av stor betydning. Hvilken bakgrunn, utdannelse og sosialt-, politisk- og faglig ståsted produsenten av lærestoffet har, vil ha noe å si for om brukeren kan stole på at kunnskapen som formidles er gyldig, at opplysninger er sanne og at de speiler en nyansert virkelighet. Posisjonen til kunnskapsformidlerne, deres verdier, holdninger og kunnskapssyn har innflytelse på lærestoffets innhold. I tradisjonelt læremateriell blir det pedagogiske ståstedet ofte giort rede for i lærestoffets forord. For å publisere digitalt læremateriale, stilles det i prinsippet ikke krav til slikt. Kunnskapen omkring et tema eller et fenomen vil ofte variere ut fra hvilken diskurs temaet er en del av. I møtet med et hvilket som helst lærestoff er det relevant å spørre seg hvilken diskurs som ligger til grunn for kunnskapsformidlingen og hvem som tjener på at studenten lærer om temaet ut fra det valgte perspektivet. Relevante spørsmål vil også være om studenten blir utsatt for politisk propaganda, eller om der er kommersielle interesser i bildet? En kritisk pedagogikk behøves dersom studentene skal lære seg å stille spørsmål omkring hvem som setter premisser for kunnskapen som formidles, og om hvilke verdier kunnskapen er tuftet på (Giroux, 2011).

Akademisk danning handler ikke om en passiv overtakelse av kultur, men en evne til kritikk og motstand og det å skape noe nytt.

(Fossland, 2015, s. 60)

Den stadig økende mengden tilgjengelige digitale læringsressurser, kombinert med et ønske fra både institusjonenes og studentenes side om å ta i bruk slikt materiale, utløser et økende behov for undervisningsopplegg der studentene lærer seg kildeanalyse, innholdsanalyse av læremateriale samt å bruke digitale læringsressurser på en kritisk, reflekterende og innovativ måte. Dette gjelder fag der lærestoffet hovedsakelig består 
av artikler og annet skriftlig materiale, men også emner der konsertopptak, opptak av mesterklasser, innspilt lyd etc. utgjør mye av lærestoffet.

Det er viktig at musikkutdanningsinstitusjonene gir sine ansatte tilstrekkelig informasjon og opplæring i bruk av digitale læringsressurser, slik at de som underviser er bevisst de digitale læringsressursenes styrker og svakheter. Vårt inntrykk er at opplæringen som tilbys når nye digitale læringsressurser tas i bruk, primært handler om læringsressursenes funksjonalitet, og at det snakkes lite om hvordan ressursene kan brukes på en måte som stimulerer studentenes evne til refleksjon og selvstendighet.

I fortsettelsen mener vi at det vil være viktig for musikkutdanningsinstitusjonene å bidra til produksjonen av digitale, pedagogiske utviklingsarbeid som støtter opp om en undervisningspraksis der refleksjon og utvikling av kreative evner hos studentene står sentralt. Slike læringsressurser kan danne en motvekt både til en undervisningstradisjon der kunnskap ofte reproduseres og konserveres, og til vår tids stadig økende informasjonsflyt og kjappe tilgang på fakta.

Kunnskap kommer bare gjennom oppfinnelser og nyoppfinnelser, gjennom den aldri hvilende, utålmodige, konstante, håpefulle undersøkelse menneskene driver med i tilværelsen, overfor tilværelsen og overfor hverandre. (Freire, 1974, s. 47)

\section{Forfatteromtale}

Maria Medby Tollefsen er universitetslektor i hørelære og er ansatt på Musikkonservatoriet ved UiT - Norges arktiske universitet. Hun er utdannet utøvende klassisk saxofonist fra Norges Musikkhøgskole og har en mastergrad i hørelære med didaktikk og praksis fra UiT. Hun fokuserer i sine FoU-arbeider på å utvikle digitale læringsressurser til bruk i hørelærefaget i høyere utdanning, blant annet gjennom nettstedet Musicificium og appen Harmoniske vendinger.

Hilde Synnøve Blix er dosent (ph.d.) i hørelære og musikkpedagogikk og ansatt på Musikkonservatoriet ved UiT - Norges arktiske universitet. Hun er utdannet musikkviter fra NTNU før hun tok sin ph.d. i musikkpedagogikk ved Norges musikkhøgskole. Hennes forskningsinteresser er knyttet til gehørutvikling, notelesing og læremidler. I tillegg har hun de seneste årene forsket på likestilling og kjønn i musikkfeltet. Hun var i 2006 redaktør for boka "Øre for musikk» (Unipub) og har senere publisert en rekke forskningsartikler og bøker nasjonalt og internasjonalt med tematikk som spenner fra gehørundervisning og notedidaktikk til likestilling og kunstnerisk utviklingsarbeid.

\section{Litteratur}

Drotner, K. (2007). Fra skolebog til læringsressource: didaktikkens medialisering. I F. Olsen (Red.), Lceremidler $i$ didaktisk sammenhang (s. 15-25). Odense: Syddanske Universitet.

Europakommisjonen, 2013: Opening up education:Innovative teaching and learning for all through new technologies and Open EducationalResources. (http://eur-lex.europa.eu/legal-content/EN/ALL/?uri=CELEX:52013DC0654) 
Europakommisjonen (2014). Modernisation of higher education. (http://ec.europa.eu/dgs/education_culture/ repository/education/library/reports/modernisation_en.pdf)

Fossland, T. (2015). Digitale laringsformer $i$ høyere utdanning. Oslo: Universitetsforlaget.

Freire, P. (1974). De undertryktes pedagogikk. Oversatt av Sissel Lie. Oslo: Gyldendal Norsk Forlag.

Giroux, H. (2011). On Critical Pedagogy. New York: Bloomsbury Academic.

Grønmo, S. (2004). Samfunnsvitenskapelige metoder. Bergen: Fagbokforlaget.

Helleve, I., Almås, A. G., \& Bjørkelo, B. (2016). Den digitale lærergenerasjonen. Oslo: Gyldendal Akademisk.

Johnson, R. B., Onwuegbuzie, A. J., \& Turner, L. A. (2007). Towards a Definition of Mixed Methods Research. Fournal of Mixed Methods Research 1(2), 112-133.

Nielsen, K., \& Kvale, S. (Red.) (1999). Mesterlere-laring som sosial praksis. Oslo: Ad Notam Gyldendal.

Ott, M., Choi, Y., Cardie, C., \& Hancock, J. T. (2011). Finding Deceptive Opinion Spam by Any Stretch of the Imagination. Proceedings of the 49th Annual Meeting of the Association for Computational Linguistics, 309-319.

Tapscott, D. (2008). Grown Up Digital. How the Net generation is changing your world. New York: McGraw-Hill.

Valtonen, T., Hacklin, S., Dillon, P., Vesisebaho, M., Kukkonen, J., \& Hietanen, A. (2012). Perspectives on personal learning environments held by vocational students. Computers and Education 58, 732-739.

Ørnes, H., Gaard, H., Refsnes, S. I., Kristiansen, T., \& Wilhelmsen, J. (2015). Digital tilstand 2014. Norgesuniversitetets skriftserie $n r .1 / 205$.

The publication charges for this article have been funded by a grant from the publication fund of UiT The Arctic University of Norway 